\title{
En preussisk Dom fra Anno 1895.
}

Det tidligere Hertugdomme Slesvigs ældgamle historiske Navn er bleven forbudt indenfor Prenssens Grænser ved den flensborgske Landrets Kjendelse af 19. September 1895. Da denne Dom har vakt berettiget $0_{p s i g t} i$ vide Kredse, aftrykker vi her dens Motivering, der har Krav paa historisk Interesse. Dommen motiveredes med folgende

\section{Grunde:}

Die Angeklagten haben gegen das Urtheil des Königlichen Schöffengerichts zu Apenrade vom 19. September 1895 , durch welches sie weyen groben Cnfugs zu je $20 . / 6$ Geldstrafe ev. 5 Tagen Haft verurtheilt sind, frist- und formgerecht Berufung eingelegt.

In der Hauptverhandlung vor dem Berufungsgerichte wurde auf Grund der Angaben der Angeklagten folgendes festrestellt:

Die Angeklagten Hanssen, Petersen und Matzen sind Verleger bezw. Redacteur und Drucker der in Apenrade erscheinenden dïnisch geschriebenen periodischen Zeitschrift „Hejmdal“. Hanssen ist ausserdem Verleger und Redacteur der periodischen Zeitschrift „Søndagsbladet, Ugeblad for Sınderjylland". Diesen Titel führt das letztgenannte Blatt auch in den Nummern 29 und 30 des vierten Jahrgangs vom 21. und 28. Juli 1895. In den Nummern 169 bis 174 des „Hejmdal“, 17. Jahrgang, von 1895 findet sich eine Rubrik mit der Ueberschrift „Fra Sønderjylland", welche Tagresneuigkeiten aus dem zwischen Eider und Königsau belegenen Theile der Provinz SchleswigHolstein, dem Herzogthum Schleswig enthïlt.

Die bezeichneten Nummern der beiden Blätter sind in gewöhnlicher Weise hergestellt und verbreitet.

Die Anklage hat hierin den Thatbestand des groben Unfugs gefunden.

Die Angeklagten geben zu, dass sie die Aufuahme 
des Wortes „Sønderjylland“ in die genamnten Blätter gewusst, Hanssen und Petersen auch, dass sie dieselbe gewollt liaben. Matzen behauptet, er habe keinen Einfluss auf den Inhalt des Blattes, als Drucker mïsse er aufnehmen, was ihm von der Redaction im Manuscript ïbersandt werde. I)ie Angeklagten bestreiten sämmtlich, sich der Verübung groben Unfugs schuldig gemacht zu haben. Sie haben übereinstimmend ausgeführt, dass der Begriff "Sonderjylland" hier nicht in politischem Sinne gehraucht werde. Dies sei der ïlteste Name für das Herzogthum Schleswior und werde dem heutigen dinischen Sprachgebrauche entsprechend in diesem Sinne angewandt. Im Sonntagsblatt insbesondere sei die Bezeichnung als Wochenblatt für Sürljütland nur deshalb gewähit, weil die I'ost eine Unterscheidung der für Schleswig erscheinenden Ausgabe desselben von der für das Königreich Dïnemark bestimnnten verlangt habe. Die Angeklagten geben die Möglichkeit zu, dass diese Bezeichnung auch eine politische Bedeutung haben kïnne, $z$. B. wenn sie in einem polemischen Artikel stände, davon sei hier aber nicht die Rede. Dass insbesondere eine Beuntuhigung des Publikums nicht angenommen werden kïnne, gehe schon daraus hervor, dass die inkriminirte Bezeichnung seit Jahren unbeanstandet von ihnen und anderweitig gebraucht sei und noch gebraucht werde.

Es sind aber diese Einwendungen der Angeliagten ohne Grund. Was zunächst die Gebriuchlicllkeit der von ihnen für Schleswig gewählten Bezeichnung betrifft, so ergiebt die Geschichte dieses Ausdrucks die Haltlosigkeit ihrer darüber aufyestellten Behauptunঞr.

Nachrlem Kaiser Conrad II. das Land zwischen Eirler und Schlei an Dänemark abgetreten hatte, gehörte das ganze heutige Schleswig zur dänischen Provinz Jütland. Alte Chronisten bezeichnen es bald ohme besondere Unterscheidung als Jütland, bald der gengraphischen Lage entsnrechend als Südjütland. Diese ältesten Bezeichnungen blieben zunächst auch dann noch bei, als durch Errichtung des dänischen Lehnsherzogthums Schleswig, welches seit 1115 einer Nebenlinie des Königshauses angehörte, für das Land zwischen Eidel und Königsau eine besondere staatsrechtliche Stellung geschaffen wurde. Ursprüunglich uannten sich die Landesherren duces Iutiae, doch kommt auch der Titel eines Herzogs von Südjütland vor, z. B. in der im Urtexte allerdings nicht erhaltenen berühmten Con- 
stitutio Waldemariana von 1326. Allmählich war es jedoch üblich geworden, das Land auch nach der aufblülienden Hauptstadt Schleswig zu benennen. Diese jüngere Bezeichnung wurde zur officiellen unter dem Grafen Gerhard dem Grossen von Holstein, welcher das Herzogthum 1320, zunïchst allerdingrs nur zeitweilig, für das Haus Schawenburg erworben hatte. Nach dem Bericht des dänischen Generalmajors Bagrgesen, vgl. Den danske Stat, Kopenhagen $1860 / 61$ S. 5, eines gewiss unverdïchtigen Zeugen, verwarf dieser Herrscher den Gebrauch des Namens Südjütland und nannte sich Herzog yon Schleswig. Wie derselbe Verfasser berichtet, wurde diese Bezeichnung allmällich die gewöhnliche und ist nach seinem Urtheil dia einzige staatsrechtlich gültige. Sie ist auch seit Christian I. von sümmtlichen dänischen Königen gebraucht worden und wird noch gegenwärtig nach Ausweis des Gothaischen Hofkalenders im grossen Titel des Königs von Dänemark gefülırt. Zwar verschwand der alte Nane nicht sofort. So nannte sich Gerhards Soln, Graf Claus, zur Bezeichnung seines Anspluchs aut Schleswig „dominus Sonder-Iutiae“. Noch im Altikel I des Kopenhagener Vergleichs vom 2. Mai 1658 abgedruckt in Falck: das Herzogthum Schleswig, Kiel 1816 S. 57 und im Artikel XXVII des Kopenhagener Friedens rom 27. Mai 1660) wird rom „Herzogthum Schlesswigr oder sonst Süder-Jütland genaunt", gesprochen. Bald darauf verschwindet die ältere Bezeichnung auch in dieser sekundären ledeutung aus den öffentlichen Urkunden. So kennt das Rendsburger Patent vom 30. Mai 1684, vgl. Falck a. a. O S. $67 \mathrm{fft}$. und bezüglich späterer Urkunden daselbst S. 81,$82 ;$ S. $85-87$; S. 88, 89; S. 90-92; S. 92, ferner die Mittheilung aus einem Manuscript des königlichen Historiographen Anclreas Höier über die Erbhuldigung des reunirten Halbschieds von Schleswig a. a. O. S. 102-104, in welchem die Vereinigung des gottorpschen Antheils von Schleswig mit dem Königlichen ausgesprochen wird, nur noch ein "Herzogthum Schleswig". Wenn Büsching in seiner Erdbeschreibung, Hamburg 1770, S. 204, den Ausdruck Sürjütland noch gebraucht, so geschieht das nur in einer Aufzählung der historischen Namen der kimbrischen Halbinsel. In der folgenden ausführlichen Beschreibung spricht er nur rom Herzogthum Schleswig und bemerkt sogar, dass der Name "Südjütland" veraltet und ungebräuchlich geworden sei, a. a. O. S. 231, 232. Wenn demgegenüber ein von deutschem Standpunkte ausgehender 
Schriftsteller Wippermann, Statsgeschichte der Herzogthümer Schleswig und Holstein, Halle 184i, S. 92, die beiden Namen für das Herzogthum noch in diesem Jahrhundert gleichwerthig gebraucht, so gescbielıt das nicht in Bezug auf die Gegenwart, sondern an einer Stelle, welche die Zeit der Königin Margaretha, wo beide Bezeichnungen noch üblich waren, schildert. In solchem Zusammenhange werden veraltete Namen sehr häufig von Geschichtsschreibern gebraucht, ohne diss diese sie auf unsere heutigen Verhältnisse anwenden wollen.

Allerdings ist dieser Versuch von anderer Seite innerhalb der letzten hundert Jahre mehrfach gemacht worden. Nach dem Erstarken des dlänischen Nationalbewusstseins und dünischer Litteratur am Ende des 18. Jahrhunderts wurde mehrfach unternommen, das Gebiet dïnischer Cultur weiter südwärts zu dehnen, ein Streben, welches die spätere Politik der eiderdänischen Partei vorbereiten half. Der erste Schriftsteller dieser Richtung war nach Werlauffs Zeugniss, Forsgg til det danske Sprogs Historie i Hertugdommet Slesvig, in den "Prisskrifter angaaende det danske Sprog i Hertugdømmet Slesvig“, Kopenhagen 1819, vgl. S. IV der Werlauffischen Vorrede, I'ontoppidan, welcher über die dïnische Sprache in „Südjütland oder dem Fürstenthum Schleswig" schrieb. Derselbe schrieb aber nach der genannten Quelle, vgl. a. a. 0., zu dem Zwecke, „die Eigenschaft des Herzogthums als integrierender Bestancltheil der dïnischen Monarchie" zu beweisen. Denselben Werth hat es, wenn Werlauff uni Outzen „Versuch einel gründlichen und unparteiischen Beantwortung der merkwürdigen Preisaufgabe über die dänische Sprache im Schleswigschen“, ebenfalls in den "Prisskrifter", sich des Namens „Südjütland“ bedienen, oder wenn er in der Vorrede eines P'reisrichters zu den Abhandlungen beider gebraucht wird. Beide Schriftsteller behandelten das Verhältniss der dänischen Sprache in Schleswig zur deutschen und die Mittel zur Ausbreitung der ersteren und erwarben sich vor einem dïnischen Preisrichtercollegium Preise, welche „ein um der dänischen Sprache Ruhm und Recht besorgter Bürger“ ausgesetzt hatte, vyl. Falck a. a. O. im Anhang S. 142. Von demselben Standpunkte aus gebrauchte Knud Aagaard, „Beskrivelse over Tørning Lehn“, Kopenhagen 1815, den Namen "Sønderjylland ". Er selbst führt in seiner Vorrede, vgl. S. VII, VIII, den Grund an, indem er als dänischer Patriot die Frage aufwirft, ob nicht der Name eines Herzor- 
thums Schleswig alozuschaffen und dafür der alte Name Südjütland wiedler einzuführen sei. Derartige Beispiele beweisen nicht, dass der alte Name des Landes sich bis in die jüngste Zeit erhalten hat, sondern im Gegentheil, dass er zu politischen Zwecken wieder aus der Vergessenheit hervorgezogen ist. Wie wenig Anklanı dieser Versuch bei den Behörden gefunden hat, geht daraus hervor, dass nach dem unglitcklichen Auscrange der schleswigholsteinischen Erhel)ung, wïhrend der Reactionszeit im Jahre 1853 das Königlich dänische Ministerium für Schleswig den Gebrauch des Wortes "Sonderjylland" in öftentlichen Actenstücken zur Bezeichnung des Herzogthums Schleswig verboten hat, vgl. Schreiben des Appellationsgerichts für das Herzogthum Schleswig in Flensburg vom 29. October 1853 an den Maristrat in Apenrade.

Seit einem Jahrzehnt etwa ist die veraltete Bezeichnung von der dänischen Presse Nordschleswigs, täglich ohne zwingende Nothwendigkeit wieder gebraucht. Diese Presse, unter welche auch die Blätter "Hejmdal“ und „Søndagsbladet" fallen, will nach der Einverleibung Schleswig-Holsteins in Preussen in der Grenzbevölkerung den Gedanken etwaiger Wiedervereinigung eines Theiles von Schleswig mit Dänemark warhhalten und ihre Aussöhnung mit den heutigen politischen Verhältnissen hintertreiben. Das ist gerichtskundig. Dazu dient ihr auch die wieder hervorgesuchte Beyeichnung Schleswigs mit Sønderjylland, in deren Wortlaut die festgehaltene Zugehörigkeit Schleswig zu Dänemark ummittelbar zum Ausdruck kommt. Diese Annahme ist nicht nur für den Fall zutreffend, dass das Wort "Sonderjylland“ in einem auch sonst polemisch gehaltenen Artikel steht, sondern bei der ausgeprägten nationaldänischen Haltung dieser Blätter auch in einem an und für sich harmlosen Zusammenhange. Dabei ist es völlig unwesentlich, ol etwa der veraltete Ausdruck sich in der neuesten dänischen Litteratur wieder eingebuirgert hat und dort vielleicht ohne politischen Nebensinn gebraucht wird. Selbst wenn, was dahingrestellt bleiben mag, die in Dänemark erscheinenden Zeitungen in diesem Sinne schreiben sollten, so darf nicht übersehen werden, dass die dänisch geschriebenen Blätter Nordschleswigs zwar in fremder sprache, aber innerhalb der deutschen Grenze für ein deutsches Publikum gesclrrieben sind und deshalb ihre Urheler die bestehenden politischen Verhältnisse wie jetler andere Staatsangehöririge anerkennen müssen. Daher ver- 
stösst die Ausgabe und Verbreitung einer Zeitschrift, in welcher der Widerspruch gegen das Bestehende so unverkennbar zum Ausdruck gebracht ist gegen die öffentliche Ordnung und es wird damit zugleich bei den heftigen politischen Gegensätzen Nordschleswigs auf die Kreise der Lesenden beunruhigend und störend eingewirkt. Die dainisch Gesinnten werden zur weiteren Bethätigung ihrer antideutschen Gesinnung, zu offener Unzufriedenheit mit den bestehenden Verhältnissen angereizt, die deutsch Gesinnten auf das tiefste verletat und geïrgert. Die Blätter haben einen grossen Lesekreis und ist deshalb die Beunruhigung nicht auf einzelne Wenige beschränkt, sondern allgemein. Diese Wirkung ist auch eine unmittelbare. Die Feststellung steht nicht im Widerspruch zu der Ansicht des Reichsgerichts, dass von eiuem strafrechtlichen Anspruche auf Achtung politischer Ueberzeurungen, deren Verletzung zu Erwiderungen und selbst den öffentlichen Frieden störenden Gewaltthätigkeiten führen könne, nicht die Rede sein dürfe, vgl. R. G. in Strafsuchen 19. $292 \mathrm{ff}$., denn hier handelt es sich nicht um die Anschauungen einer politischen Partei, deren Erörterung an und für sich die Freiheit gewaht bleiben soll, sondern un Anschauungen, deren Verwirklichung eine Anklage wegen Hochverraths nach sich ziehen müsste.

Bei der gerichtskundigen politischen Wirksamkeit der Angeklagten ist ferner angenommen, nicht nur, dass sie den eingetretenen Erfolg bei gehöriger Ueberlegung hätten voraussehen müssen, also verschuldet, sondern auch, dass sie ihn vorsützlich herbeigeführt haben. Dies gilt auch bezüglich des Angeklagten Matzen, welcher als Drucker an und für sich zwar auf den Inhalt der ihm zur Drucklegung vorgelegten Schriften keinen Einfluss hatte, im vorliegenden Fall aber mit dieser seiner Schutzbehauptung keinen Glauben gefunden hat, weil er langjüihriger Redacteur und Herausgeber des "Hejmalal gewesen ist und noch heute innerhalb der dünischen Agitation nach Kenntniss des Gerichts eine bestimmende Stellung einnimmt.

Er hat daher mit Petersen und Hanssen zur Ausgabe und Verbreitung der Zeitung "Hejmdal" zusammen gewirkt und Jeder von ihnen ist als Thïter zu bestrafen. Ebenso Hanssen bezüglich der Ausgabe und Verbreitung von Søndagsbladet. Die Verantwortlichkeit der simmtlichen Angeklagten wird dadurch nicht aufgehoben, dass sie ihr 'Thun Jahre lang unbehelligt getrieben haben. 
Die einzelnen in Betracht kommenden Fälle sind bei jedem Angeklagten als einheitliche That angeselıen.

Somit ist thatsïchlich festgestellt, dass im Juli 1895 zu Apenrade

1) die Angeklagten gemeinschaftlich dadurch, dass sie in der daselbst erscheinenden von Hanssen herausgegebenen periodischen Zeitschrift „Hejmdal “ $\mathrm{Nr}$. 169 bis $17 \pm$ vou 1895 ,

2) der Angeklagte Hanssen dadurch, dass er in der periodischen Zeitschrift „Søndagsbladet“ Nr. 29 und 30 von 1895 die Bezeichnung Schleswigs als „Sønderjylland" gebraucht und die Zeitschriften mit dieser Bezeichnung ausgegeben und verbreitet haben groben Unfug verübt haben.

Uebertretung gegen $\$ s 360^{\prime \prime}, 47,73$ St. G. B., $\$ 20$ Ges. vom 7. Mai 1874.

Bei der Strafzumessung fiel zwar zu Gunsten der Angeklagten ins Gewicht, dass sie Jahre lang offenkundig ihre Thätigkeit ausgeübt haben und dabei von den Behörden nicht gestört worden sind. Hierdurch ist bei ihnen das Gefülıl der Strafbarkeit ihres Thuns geschwächt worden. Das Gericht würde aus diesem Grunde eine Erhöhung der vom Vorderrichter erkannten Strafe auch dann nicht vorgenommes haben, wenn es hierzu durch Einlegung der Berufung auch von Seiten der Staatsanwaltschaft in der Lage gewesen wäre. Zu einer Herabsetzung der Strafen lag aber eine Veranlassung ebensowenig vor. Denn der Umstand, dass trotz der Feststellung in der Fntscheidung gegen Andresen vom $\frac{26 \text {. April }}{26 \text {. Juni }} 1895$, Actenzeichen 0 65/95 der incriminirte Ausdruck weiter gebraucht worden ist, die zu Grunde liegende Absicht, eine ruhige ordnungsliebende Bevölkerung aufzuhetzen, sowie Matzens und Hanssens Vorstrafen waren strafschärfend zu berücksichtigen, die vom Vorderichter erkannte Geldstrafe ist deshalb angewessen.

Wegen der Kosten ist nach $\S 505$ St. P. 0. entschieden worden.

(gez.) Muhl. Claudius. von Ahlefeld.

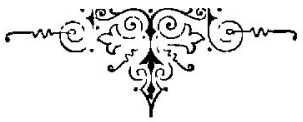

